\title{
Synthesis of temperature-resistant and salt- tolerant surfactant SDB-7 and its performance evaluation for Tahe Oilfield flooding (China)
}

\author{
Guo Jixiang ${ }^{1 *}$, Shi $\mathrm{Xiao}^{2}$, Yang Zuguo ${ }^{3}$, Cao Jingjing ${ }^{4}$, Wang $\mathrm{Lei}^{3}$ and Yin \\ Ying $^{1}$ \\ ${ }^{1}$ Enhanced Oil Recovery Institute, China University of Petroleum, Beijing 102249, China \\ ${ }^{2}$ Beijing Research \& Development Center, Sinopec Lubricant Company, LTD, Beijing 100085, China \\ ${ }^{3}$ Engineering Technology Institute, Northwest Oilfield Company, SINOPEC, Urumchi 830011, China \\ ${ }^{4}$ Economy and Information Technology Commission of Bayingol Mongolian Autonomous Prefecture, Autonomous \\ Prefecture, Korla 841000, China
}

(C) China University of Petroleum (Beijing) and Springer-Verlag Berlin Heidelberg 2014

\begin{abstract}
In order to improve the enhanced oil recovery of high-temperature and high-salt oilfields, a novel temperature-resistant and salt-tolerant surfactant (denoted as SDB-7) was synthesized and evaluated for the Tahe Oilfield (Xinjiang, China), which is representative of high-temperature and high-salt oilfields. It has a central reservoir temperature of $140{ }^{\circ} \mathrm{C}$ and salinity of $22.6 \times 10^{4} \mathrm{mg} / \mathrm{L}$. The temperature-resistant and salt-tolerant performance, interfacial activity, oil displacement efficiency, aging properties, and adsorption properties of the synthesized surfactant were evaluated for Tahe Oilfield flooding. The results showed that the SDB-7 was temperature-resistant and salt-tolerant capacity of $140{ }^{\circ} \mathrm{C}$ and $22.6 \times 10^{4} \mathrm{mg} /$ $\mathrm{L}$, respectively, oil displacement efficiency under static condition of $84 \%$, and adsorption loss of $0.4 \mathrm{mg} /$ $\mathrm{g}$ (less than $1 \mathrm{mg} / \mathrm{g}$-oil sand). In the heat aging experiment (under the temperature of $140{ }^{\circ} \mathrm{C}$ for 60 days), the oil-water interfacial tension and oil displacement efficiency of SDB-7 were almost unchanged. The oil displacement experiments showed that, under the temperature of $140{ }^{\circ} \mathrm{C}$ and the salinity of $22.6 \times 10^{4} \mathrm{mg} / \mathrm{L}$, the surfactant SDB-7 can enhance oil recovery by $14.5 \%$ after water flooding,suggesting that SDB-7 has a promising application in high temperature and high salinity (HT/HS) reservoir.
\end{abstract}

Key words: Temperature-resistance, salt-tolerance, surfactant, oil displacement experiments, EOR

\section{Introduction}

Surfactants play an important role in chemical oil displacement processes. They can reduce the oil/water interfacial tension and improve capillary numbers to improve oil recovery dramatically (Cardoso et al, 2007; Zhao et al, 2010). Oil displacement surfactants mainly include anionic surfactants, cationic surfactants, nonionic surfactants, nonionic-anionic compound surfactants and polymer surfactants (Torres et al, 2011; Masahiko et al, 2000; Graciaa et al, 2003; Pasc-Banu et al, 2004).

In recent years, temperature resistant and salttolerant surfactants for enhanced oil recovery (EOR) have been investigated by numerous researchers (Chen and Huang, 2010; Iglauer et al, 2010; Han, 2011; Aoudia et al, 2010; Zhu et al, 2012).

For tertiary oil recovery, improving temperature-resistance and salt-tolerance properties of surfactants is important

*Corresponding author. email: guojx002@163.com

Received March 23, 2014 and urgent, and has practical significance for high salinity reservoirs. At present, there are many different kinds of surfactants, but they have either heat resistance or salt tolerance performance but rarely both (Leng et al, 2008; Levitt et al, 2011; Li et al, 2010; Rong et al, 2010; Shen et al, 2011). For example, surfactant oxyethylated alkylphenol made from didecyl sulfonic sodium succinate and tripropylene can enhance the temperature resistance of oil displacement system (Zhang et al, 2005); poly-oxyethyl alkyl sulfate and petroleum sulfonate surfactant complex system can greatly improve the salt resistance of oil displacement system (Guo et al, 2009). The temperature resistance of some newly synthesized sufactants is generally about $85^{\circ} \mathrm{C}$ (Zheng et al, 2009) and the highest temperature resistance is $90{ }^{\circ} \mathrm{C}$ (Sha et al, 2007). Surfactants with a temperature resistance of $100{ }^{\circ} \mathrm{C}$ or higher are rarely reported. The salt tolerance of recently developed sufactants is generally below $10.0 \times 10^{4} \mathrm{mg} / \mathrm{L}$ and the highest value can reach up to $16.0 \times 10^{4} \mathrm{mg} / \mathrm{L}$ (Yang et al, 2009; Zhao et al, 2012). However, surfactants with both heat resistant and salt tolerant performance are rare. 
Aiming at the high-temperature and high-salt characteristics of Tahe Oilfield (Xinjiang, China), which is a representative of high-temperature and high-salt oilfield with the central reservoir temperature of $140{ }^{\circ} \mathrm{C}$ and salinity of $22.6 \times 10^{4} \mathrm{mg} / \mathrm{L}$, a temperature-resistant and salt-tolerant surfactant SDB-7 was synthesized, and the properties of SDB-7 were evaluated.

\section{Experimental}

\subsection{Materials and instruments}

\section{Materials:}

Diphenyl ether, bromododecane, and chlorosulfuric acid were were chemically pure reagents.

Anhydrous aluminum chloride, sodium chloride $(\mathrm{NaCl})$, and calcium chloride $\left(\mathrm{CaCl}_{2}\right)$, were analytical reagent grade.

Surfactant SDB-7 for EOR was synthesized with diphenyl ether and bromododecane in the presence of anhydrous aluminum chloride as a catalyst and chlorosulfuric acid as sulfonating agent. The molar ratio of diphenyl ether to bromododecane was $1: 1$.

Oil samples, formation water, oil sands and core samples (natural cores) were from the Tahe Oilfield, Xinjiang, China.

Instruments:

PIC-10A ion chromatograph (Qingdao Puren Instrument Co., Ltd., China); Thermo-Finnigan Trace gas chromatograph (Thermo Electron Corporation, USA); JJ2000B spinning drop interfacial tensiometer (Shanghai Zhongchen Digital Technic Apparatus Co., Ltd., China); UV-2100 ultraviolet spectrophotometer (Younike (Shanghai) Instrument Co., Ltd.); RD IV pressurization vessel (Nanjing Jiumen Autocontrol Technology Co., Ltd., China); Core displacement equipment (Jiangsu Huaan Scientific Research Devices Co., Ltd., China).

\subsection{Experimental methods}

\subsubsection{Reservoir water quality analysis}

The ionic compositions and contents of formation water were measured by ion chromatography.

\subsubsection{Carbon number distribution of crude oil in reservoir}

The carbon number distribution of crude oil was determined by the standard method SY/T 5779-2008 (Analytical method of hydrocarbons in petroleum and sediment by gas chromatography, China) using a ThermoFinnigan Trace gas chromatograph.

\subsubsection{Evaluation of interfacial activity}

The oil-water interfacial tension was determined by Spinning Drop method. Under the action of centrifugal force, gravity and interfacial tension, low-density oil droplets in a high-density liquid can form oval or round columns (Ibrahim et al, 2006; Zhang et al, 2007). According to the BashforthAdams equation, the interfacial tension is defined as:

$$
\sigma=\frac{\omega^{2} r^{3} \Delta \rho}{4}
$$

where $\sigma$ is the interfacial tension $(\mathrm{N} / \mathrm{m}), \Delta \rho$ is the liquid density difference $\left(\mathrm{g} / \mathrm{cm}^{3}\right), r$ is the cylindrical radius $(\mathrm{mm})$, and $\omega$ is the rotate speed (r/min).

\subsubsection{Evaluation of salinity tolerance of surfactant}

At ambient temperature, $0.1 \%$ (mass fraction) surfactant solution was prepared, then different concentrations (in the range from $100 \mathrm{mg} / \mathrm{L}$ to $200,000 \mathrm{mg} / \mathrm{L}$ ) of $\mathrm{NaCl}$ or $\mathrm{CaCl}_{2}$ solutions was added to the surfactant solution, and stirred and then centrifuged for $10 \mathrm{~min}$ at 2,000 r/min. Precipitation of solute may occur as the solution salinity increases. The concentration of $\mathrm{NaCl}$ or $\mathrm{CaCl}_{2}$ when precipitates begin to appear is the limit of the sodium (calcium) salinity resistance of the surfactant (Xin et al, 2008).

\subsubsection{Evaluation of long-time thermal stability of surfactant}

High temperature aging of $0.1 \mathrm{wt} \%$ petroleum sulfonate solution and SDB-7 solution was performed at $140{ }^{\circ} \mathrm{C}$ for 3 h. The interfacial tensions between the surfactant solution and crude oil before and after high temperature aging were determined. The oil washing efficiency of SDB-7 was also evaluated.

In the oil washing evaluation experiment, artificial oil sand was prepared by mixing quartz sand and crude oil uniformly in certain ratios. The surfactant solutions (in formation water) and the artificial oil sand (made from quartz sand and crude oil), were mixed in a $100 \mathrm{~mL}$ cylinder in the mass ratio of 2 to 1 . Then the cylinder was placed in an ultrasonic bath for $15 \mathrm{~min}$. The volume of oil washed from oil sand by the surfactant solution was recorded, and the oil washing efficiency of the surfactant was calculated by using Eqs. (2) and (3) (Guo and Gao, 2011).

The oil content in artificial oil sand:

$$
A=\frac{M_{1}}{M_{1}+M_{2}} \times 100 \%
$$

The oil washing efficiency:

$$
B=\frac{\rho \times V}{m \times A} \times 100 \%
$$

where $M_{1}$ is the mass of crude oil in artificial oil sand $(\mathrm{g}), M_{2}$ is the mass of quartz sand in artificial oil sand $(\mathrm{g}) ; \rho$ is the cruel oil density $\left(\mathrm{g} / \mathrm{cm}^{3}\right) ; V$ is the washed oil volume $(\mathrm{mL}), m$ is the mass of oil sand in scale cylinder $(\mathrm{g})$.

\subsubsection{Evaluation of adsorption performance of surfactant}

In the oil displacement process, the loss of surfactant due to the adsorption by oil sand directly affects oil displacement efficiency. It is important to determine the surfactant adsorption in natural oil sand. The static adsorption of surfactant on natural oil sand surfaces can be calculated according to the change in the concentration of surfactant solution before and after adsorption (Yang et al, 2006). The mass fraction of adsorbed surfactant was measured with a UV-2100 ultraviolet spectrophotometer.

$$
\Gamma=\frac{\left(C_{0}-C\right) \times M}{m} \times 100 \%
$$

where $\Gamma$ is the adsorption capacity $(\%) ; C_{0}$ is the initial mass fraction of adsorbate solution (\%), $C$ is the instantaneous mass fraction of adsorbate solution (\%), $M$ is the mass of the adsorbate solution $(\mathrm{g}), m$ is the mass of natural oil sand $(\mathrm{g})$. 


\subsubsection{Oil displacement experiment}

The core displacement experiment was carried out on core displacement equipment. The displaced oil volume at $140{ }^{\circ} \mathrm{C}$ using different oil displacement agents was measured ( $\mathrm{Zhu}$ et al, 2010; Puerto et al, 2012; Wang et al, 2010) and the oil displacement efficiency was calculated.

The displacement experiment procedure is as follows.

1) Weigh the core, measure the diameter and length of the core with a vernier gauge.

2) Evacuate the core for $8 \mathrm{~h}$, and then saturate it with Tahe formation water for $6 \mathrm{~h}$, and then weigh the core and calculate the porosity of the core.

3) Put the core in grippers, check the valve and the closure of the interface, adjust the back-pressure valve to raise the back-pressure to $10 \mathrm{MPa}$, and leave it at a constant temperature of $140{ }^{\circ} \mathrm{C}$ for $1 \mathrm{~h}$ to determine the core permeability $K$.

4) Inject crude oil to the core which had been saturated with formation water, until the injected oil volume reached 20 pore volumes $(\mathrm{PV})$, record the water volume $V$ displaced from the core, which is the volume of crude oil saturated in the core. Then saturate the core with oil for 1 to 2 days.

5) Water flooding: inject Tahe oilfield formation water into oil-saturated core until no oil comes out, then record the oil volume $\left(V_{1}\right)$ displaced.

6) Surfactant flooding: inject the oil displacement surfactant until no oil comes out. Then record the oil volume $\left(V_{2}\right)$ displaced with surfactant.

7) Subsequent water flooding: inject formation water again until no oil comes out. Then record the oil volume, $V_{3}$.

The oil displacement efficiency by water flooding:

$$
\eta_{1}=\frac{V_{1}}{V} \times 100 \%
$$

The oil displacement efficiency by surfactant flooding and subsequent water flooding:

$$
\Delta \eta=\frac{V_{2}+V_{3}}{V} \times 100 \%
$$

The total oil displacement efficiency: $\eta=\eta_{1}+\Delta \eta$

\section{Results and discussion}

\subsection{Analysis of formation water}

The analysis results of Tahe oilfield formation water are shown in Table 1 . The total salinity is $22.6 \times 10^{4} \mathrm{mg} / \mathrm{L}$, the total concentration of $\mathrm{Ca}^{2+}$ and $\mathrm{Mg}^{2+}$ is $1.2 \times 10^{4} \mathrm{mg} / \mathrm{L}$.

Table 1 The content of ions and suspended matter of formation water in Tahe oilfield

\begin{tabular}{cccccccccccccc}
\hline Items & $\mathrm{Na}^{+}$ & $\mathrm{K}^{+}$ & $\mathrm{Al}^{3+}$ & $\mathrm{Ca}^{2+}$ & $\mathrm{Mg}^{2+}$ & $\mathrm{Fe}$ & $\mathrm{SO}_{4}^{2-}$ & $\mathrm{Cl}^{-}$ & $\mathrm{HCO}_{3}^{-}$ & $\mathrm{S}^{2-}$ & $\mathrm{CO}_{3}^{2-}$ & $\mathrm{Suspended} \mathrm{matter}^{2-}$ \\
\hline $\begin{array}{c}\text { Content } \\
\mathrm{mg} / \mathrm{L}\end{array}$ & $7.21 \times 10^{4}$ & 445 & $<0.09$ & $1.11 \times 10^{4}$ & 815 & 7.34 & 303 & $1.41 \times 10^{5}$ & 66.8 & 0.020 & $<0.1$ & 108 \\
\hline
\end{tabular}

\subsection{Carbon number distribution of crude oil}

The results of the carbon number distribution of Tahe crude oil are presented in Fig. 1. The four crude oil samples from different wells in the same area of the Tahe Oilfield have similar carbon number distribution trend and the carbon number is mainly distributed around $\mathrm{C}_{7}-\mathrm{C}_{20}$. The carbon number of the synthesized surfactant molecules should match approximately the carbon number distribution of Tahe crude

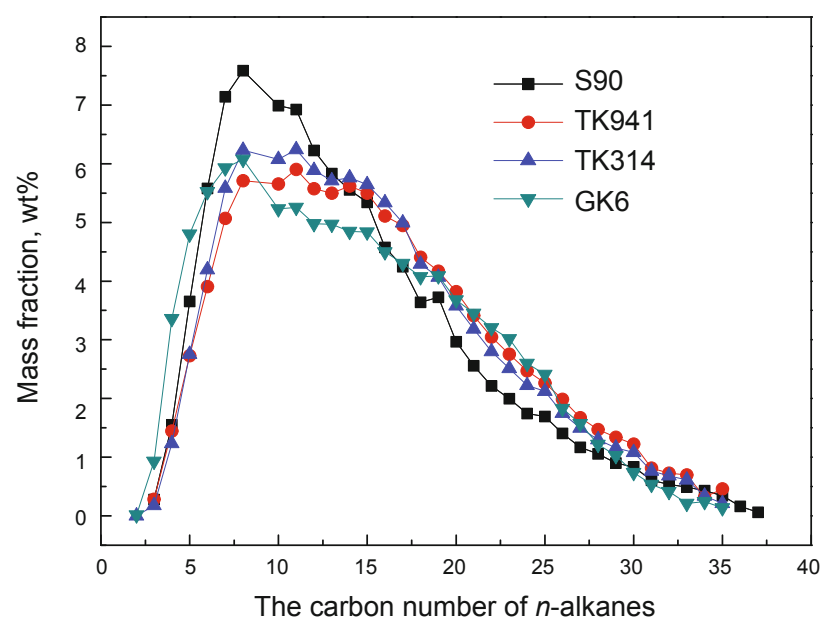

Fig. 1 The $n$-alkane carbon number distribution of Tahe crude oil oil. Surfactant nonpolar carbon chain and carbon number distribution of crude oil are high close, which can increase the lipophilicity of surfactant and improve the concentration of surfactant on the interface of oil-water.

\subsection{Performance evaluation of surfactant}

The oil displacement surfactant SDB-7 was developed aimed at the features of the Tahe oil reservoir: high temperature $\left(140{ }^{\circ} \mathrm{C}\right)$, high salinity $\left(22.6 \times 10^{4} \mathrm{mg} / \mathrm{L}\right)$ and oil properties.

\subsubsection{Salt-resistance performance}

The salt-resistance of the surfactant SDB-7 was determined. The salinity tolerance of SDB-7 solution (i.e. $180,000 \mathrm{mg} / \mathrm{L}$ for sodium salts, $21,000 \mathrm{mg} / \mathrm{L}$ for calcium salts) was significantly better than that of petroleum sulfonate $(14,000 \mathrm{mg} / \mathrm{L}$ for sodium salts, $80 \mathrm{mg} / \mathrm{L}$ for calcium salts). The SDB-7 solution prepared by using formation water as solvent was clear and transparent, indicating that SDB-7 can be used with high salinity formation water.

\subsubsection{Long-time temperature-resistance and salt-resistance performance}

The influence of aging time on oil-water interfacial tension and oil washing efficiency was investigated, and the results are presented in Fig. 2 and Table 2. 


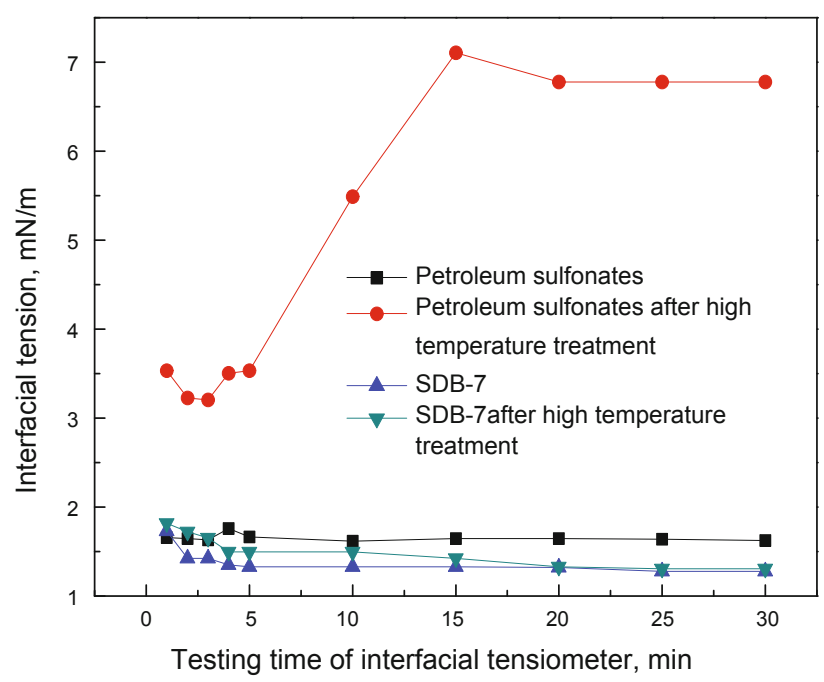

(a) The interfacial tension variations of surfactants $\left(140{ }^{\circ} \mathrm{C}, 3 \mathrm{~h}\right)$

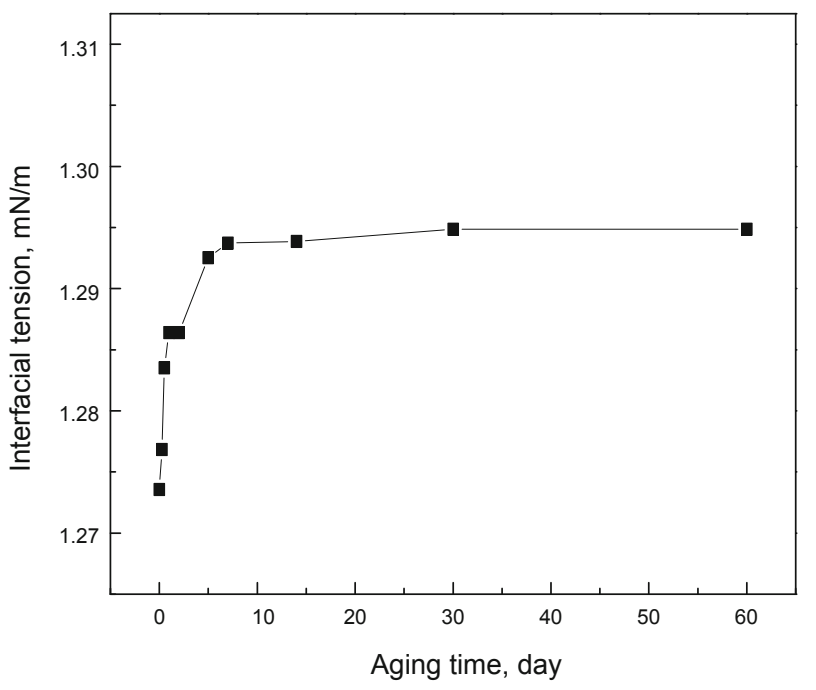

(b) The interfacial tension variations of SDB-7 $\left(140{ }^{\circ} \mathrm{C}, 60 \mathrm{~d}\right)$

Fig. 2 The interfacial tension variations of surfactants in high-temperature-ageing process

Table 2 Influence of aging time on oil washing efficiency of SDB-7

\begin{tabular}{ccc}
\hline $\begin{array}{c}\text { Aging time at } 140{ }^{\circ} \mathrm{C} \\
\text { day }\end{array}$ & $\begin{array}{c}\text { Washing oil volume } \\
\mathrm{mL}\end{array}$ & $\begin{array}{c}\text { Oil washing efficiency } \\
\%\end{array}$ \\
\hline 0 & 2.0 & 84.0 \\
10 & 2.0 & 84.0 \\
60 & 2.0 & 84.0 \\
\hline
\end{tabular}

Note: The oil washing efficiency of formation water (without SDB-7) is $5.3 \%$

As seen in Fig. 2(a) and (b), the oil-water interfacial tension of petroleum sulfonates increased significantly after $3 \mathrm{~h}$ of high temperature aging, and their interface activity declined; while the oil-water interfacial tension of SDB-7 surfactant was almost unchanged by aging, demonstrating strong heat resistance.

As shown in Table 2, the oil washing efficiency of SDB7 formation water solution (84\%) was greatly higher than that of formation water without SDB-7 (5.3\%), and it remained unchanged after 60 days of high temperature $\left(140{ }^{\circ} \mathrm{C}\right)$ aging, indicating that SDB-7 had excellent long-term temperatureand salt-resistance performance.

\subsubsection{Adsorption performance}

SDB-7 solutions with different concentrations were prepared and adsorbed on oil sands at $140{ }^{\circ} \mathrm{C}$ for $6 \mathrm{~h}$, and then centrifuged. The absorbance value of the supernatants obtained from centrifugal separation was measured. The static adsorption capacity on the surface of oil sands was calculated. The results are shown in Fig. 3.
As shown in Fig. 3, the adsorption capacity of SDB7 surfactant solution was $0.4 \mathrm{mg} / \mathrm{g}$-oil sands, less than 1 $\mathrm{mg} / \mathrm{g}$-oil sands, meeting the requirements for adsorption performance of surfactant for EOR.

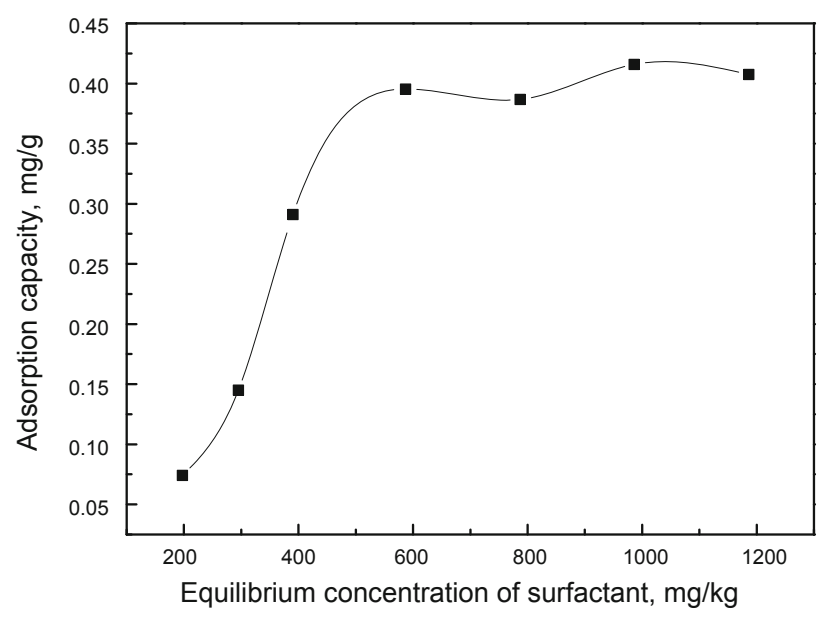

Fig. 3 The adsorption isothermal curve of SDB-7 on the surface of oil sands

\subsubsection{Oil displacement efficiency}

The oil displacement efficiency of SDB-7 and petroleum sulfonate was evaluated using natural cores at $140^{\circ} \mathrm{C}$. The physical parameters of the natural cores and the displacement experiment results are presented in Table 3.

Table 3 Physical parameters of core and result of displacement experiment

\begin{tabular}{ccccccccccc}
\hline No. & $\begin{array}{c}\text { Diameter } \\
\mathrm{cm}\end{array}$ & $\begin{array}{c}\text { Length } \\
\mathrm{cm}\end{array}$ & $\begin{array}{c}\text { Porosity } \\
\%\end{array}$ & $\begin{array}{c}\text { Number of pore } \\
\text { volume injection } \\
(\mathrm{PV})\end{array}$ & $\begin{array}{c}\text { Permeability } \\
\times 10^{-3} \mu \mathrm{m}^{2}\end{array}$ & $\begin{array}{c}\text { Injected } \\
\text { system }\end{array}$ & $\begin{array}{c}\text { Oil saturation } \\
\%\end{array}$ & $\begin{array}{c}\text { Temperature } \\
{ }^{\circ} \mathrm{C}\end{array}$ & $\begin{array}{c}\text { Water flooding } \\
\text { recovery } \eta_{1} \\
\%\end{array}$ & $\begin{array}{c}\text { EOR after water } \\
\text { flooding } \Delta \eta, \%\end{array}$ \\
\hline 1 & 2.50 & 7.13 & 15.2 & 0.35 & 234 & $\mathrm{~A}$ & 52.7 & 140 & 29.8 \\
2 & 2.51 & 5.16 & 17.3 & 0.4 & 129.8 & $\mathrm{~B}$ & 52.2 & 140 & 44.6 & 1.4 \\
3 & 2.51 & 6.85 & 17.6 & 0.4 & 91.5 & $\mathrm{~B}$ & 44.4 & 140 & 35.7 \\
\hline
\end{tabular}

Notes: 1) water flooding and subsequent water flooding using Tahe oilfield formation water; 2 ) Injected system A: water flooding $+0.3 \mathrm{wt} \%$ petroleum sulfonate solution in deionized water+subsequent water flooding; 3 ) Injected system B: water flooding $+0.3 \mathrm{wt} \%$ surfactant SDB-7 solution in Tahe formation water + subsequent water flooding 
Table 3 showed that the crude oil recovery was approximately $30 \%$ by water flooding, and the oil recovery increased by $14.5 \%$ by SDB-7 after water flooding, more significantly than that of petroleum sulfonates $(1.4 \%)$, indicating surfactant SDB-7 would be suitable to HT/HS reservoir and meeting the requirements for enhanced oil recovery after water flooding of reservoir.

\section{Conclusion}

1) Temperature-resistant (to $140{ }^{\circ} \mathrm{C}$ ) and salt-tolerant (to $22.6 \times 10^{4} \mathrm{mg} / \mathrm{L}$ ) surfactant SDB-7 was developed. The heat resistance and salt resistance of SDB-7 are far better than those of petroleum sulfonates.

2) The results of long-time temperature-resistance and salt-resistance performance show that the oil-water interfacial tension and oil washing efficiency of SDB-7 were basically unchanged after high temperature $\left(140{ }^{\circ} \mathrm{C}\right)$ and high salt $\left(22.6 \times 10^{4} \mathrm{mg} / \mathrm{L}\right)$ aging for 60 days, presenting excellent temperature resistance. The adsorption loss of SDB-7 is $0.4 \mathrm{mg} / \mathrm{g}$ on oil sands, satisfying the requirements of oil displacement surfactants adsorption properties for the reservoir.

3) The results of core displacement experiments (temperature of $140{ }^{\circ} \mathrm{C}$, salinity of $22.6 \times 10^{4} \mathrm{mg} / \mathrm{L}$ ) show that the oil recovery increment of SDB-7 after water flooding is $14.5 \%$. SDB-7 has excellent properties for applications in high temperature and high salinity reservoirs.

\section{Acknowledgements}

The authors would like to thank the China National High Technology Research and Development Program (No. 2013AA064301), and National Natural Science Foundation of China (No. 51274210) for financial support.

\section{References}

Aoudia M, Al-Maamari R S, Nabipour M, et al. Laboratory study of alkyl ether sulfonates for improved oil recovery in high-salinity carbonate reservoirs: a case study. Energy \& Fuels. 2010. 24(6): 3655-3660

Cardoso C B, Silva R C A and Pires A P. The role of adsorption isotherms on chemical-flooding oil recovery. SPE Annual Technical Conference and Exhibition, 11-14 November 2007, Anaheim, California, U.S.A. (SPE 109642)

Chen X R and Huang F X. Research progress of temperature-resistant and salt-tolerant surfactants for enhanced oil recovery. Petrochemical Technology. 2010. 39(12): 1307-1312 (in Chinese)

Graciaa A, Creux P, Lachaise J, et al. Competitive adsorption of surfactant at air/water interfaces. Journal of Colloid and Interface Science. 2003. 261(2): 233-237

Guo D H, Guan T, Xin H C, et al. Field application of surfactant exhibiting thermal stability and salt endurance for oil replacement. Fine and Specialty Chemicals. 2009. 17(10): 13-14 (in Chinese)

Guo J X and Gao X H. The optimization for surfactant oil displacement system in low permeability reservoirs. Applied Chemical Industry. 2011. 40(6): 940-945 (in Chinese)

Han Y G. Chemicals in heat tolerate and salt resistant flooding.
Southwest Petroleum University, Sci. Tech. Ed. 2011. 33(3): 149153 (in Chinese)

Ibrahim Z, Manap A A A, Hamid P A, et al. Laboratory aspect of chemical EOR processes evaluation for Malaysian oilfields. SPE Asia Pacific Oil \& Gas Conference and Exhibition, 11-13 September 2006, Adelaide, Australia (SPE 100943)

Iglauer S, Wu Y F, Shuler P, et al. New surfactant classes for enhanced oil recovery and their tertiary oil recovery potential. Journal of Petroleum Science and Engineering. 2010. 71(1): 23-29

Leng Q, Shang C H, Li J, et al. A low cost compounded surfactant for EOR in higher temperature and middle low permeability sandstone reservoirs in Zhuangxi. Oilfield Chemistry. 2008. 25(1): 71-73 (in Chinese)

Levitt D, Dufour S, Pope G A, et al. Design of an ASP flood in a hightemperature, high-salinity, low-permeability carbonate. International Petroleum Technology Conference, 15-17 November 2011, Bangkok, Thailand (IPTC 14915)

LiN, Liu H T, Fu X, et al. Study on the dynamic interfacial tension between dinonylphenol polyoxypropylene ether sulfonate-sodium carbonate system and Zhuangxi crude oil. Journal of Xi'an Shiyou University (Natural Science Edition). 2010. 25(1): 77-80 (in Chinese)

Masahiko A, Kazuhiko T, Hideki S, et al. Thermoresponsive viscoelasticity of concentrated solutions with a fluorinated hybrid surfactant. Langmuir. 2000. 167: 47-60

Pasc-Banu A, Raluca S, Muriel B, et al. Microstructures in aqueous solutions of hybrid fluorocarbon/hydrocarbon catanionic surfactants. Colloids and Surfaces A: Physicochemical and Engineering Aspects. 2004. 242(1): 195-201

Puerto M, George J H, Clarence A M, et al. Surfactant systems for EOR in high-temperature, high-salinity environments. SPE Journal. 2012. 17(1): 11-19

Rong X M, He W D, Li G H, et al. Synthesis and performance evaluation of octylphenol polyoxyethylene ether phosphate. Journal of Xi' an Shiyou University (Natural Science Edition). 2010. 25(1): 71-76 (in Chinese)

Sha O, Zhang W D, Chen Y F, et al. Synthesis and characterization of alkylphenol sulfonic polyxyethylene ether sulfonate displacement agent. Fine Chem. 2007. 24(11): 1069-1073 (in Chinese)

Shen Z Q, Li Y C, Sha O, et al. Synthesis and properties of nonionicanionic gemini surfactants with high activity. Advances in Fine Petrochemicals. 2011. 12(9): 25-29 (in Chinese)

Torres L, Moetezurna A, Avendano J R, et al. Comparison of bio-and synthetic surfactants for EOR. Journal of Petroleum Science and Engineering. 2011. 76(1): 6-11

Wang D, Liu C, Wu W, Wang G, et al. Novel surfactants that attain ultralow interfacial tension between oil and high salinity formation water without adding alkali, salts, co-surfactants, alcohol and solvents. SPE EOR Conference at Oil \& Gas West Asia. 11-13 April 2010. Muscat. Oman (SPE 127452)

Xin Y C, Qiu Z Z, Zhang S J, et al. Salt-resistance property and application of $\alpha$-olefine polyether sulfonate. Journal of Chemical Industry and Engineering (China). 2008. 59(11): 2935-2940 (in Chinese)

Yang X P, Guo D H, Xin H C, et al. Preparation of aliphatic alcohol/ alkyl phenol polyoxyethylene ether sulphonates. Speciality Petrochemicals. 2009. 26(5): 8-11 (in Chinese)

Yang Y, Li M Y, Lin M Q, et al. Study on surface property and adsorption of nonionic Gemini surfactants on solid-liquid interface. Journal of China University of Petroleum (Edition of Natural Science). 2006. 30(3): 123-125 (in Chinese) 
Zhang F Y, Yang G, Liu Y B, et al. Development of chemical oil displacement agent for high temperature and high salinity reservoir. Advances in Fine Petrochemicals. 2005. 6(5): 8-11 (in Chinese)

Zhang Y P, Sayegh S G and Huang S. Effect of oil/brine ratio on interfacial tension in surfactant flooding. Petroleum Society's 8th Canadian International Petroleum Conference. 12-14 June 2007. Calgary. Alberta

Zhao L, Li A F, Chen K, et al. Development and evaluation of foaming agents for high salinity tolerance. Journal of Petroleum Science and Engineering. 2012. 81: 18-23

Zhao T T, Gong H J, Xu G Y, et al. Investigation of salt tolerance of anionic surfactants in aqueous solutions. Oilfield Chemistry. 2010.
27(1): 112-118 (in Chinese)

Zheng X N, Ye Z B, Ye Z R, et al. Synthesis of an oil-displacing agent with dendritic molecules and its evaluation. Xinjiang Petroleum Geology. 2009. 30(05): 637-640 (in Chinese)

Zhu Y Y, Hou Q F, Yuan H, et al. Synthesis and properties of petroleum sulfonates for weak alkali ASP/alkali-free SP combination flooding. Asia Pacific Oil and Gas Conference and Exhibition, 18-20 October 2010, Brisbane, Queensland, Australia (SPE 133419)

Zhu Y Y, Ning Z L, Hou Q F, et al. Synthesis and interfacial activity of alkyl polyoxypropylene sulfonate for chemical combination flooding. Advanced Materials Research. 2012. 550: 3-9

(Edited by Zhu Xiuqin) 